\title{
EFEITO DA COMPOSIÇÃO DO SOLVENTE SOBRE A ESTABILIDADE DE PROTEÍNAS EM SOLUÇÕES AQUOSAS
}

Lúbia Cristina Fonseca, Natássia Caroline Resende Corrêa, Mario da Silva Garrote-Filho, Cleine Chagas da Cunha e Nilson Penha-Silva*

Instituto de Genética e Bioquímica, Universidade Federal de Uberlândia, CP 593, 38400-902 Uberlândia - MG, Brasil

Recebido em 14/3/05; aceito em 21/7/05; publicado na web em 8/2/06

\begin{abstract}
EFFECTS OF THE SOLVENT COMPOSITION ON THE STABILITY OF PROTEINS IN AQUEOUS SOLUTIONS. A protein presents a native $(\mathrm{N})$ macro state, which is functionally active, in equilibrium with the denatured (D) macro state, which is devoid of biological activity. An ensemble of microstates forms each macrostate. The denatured state comprises a greater ensemble of microstates than the native macrostate. The N-D equilibrium can be affected by several factors, that comprise the purity of the water, temperature, $\mathrm{pH}$ and solute concentration. This work discusses the influence of osmolytes and chaotropics on the N-D equilibrium in aqueous solutions.
\end{abstract}

Keywords: chaotropics; protein stability; osmolytes.

\section{INTRODUÇÃO}

As proteínas são fundamentais para os seres vivos e podem desempenhar diversas funções, desde a organização estrutural de uma célula até as organizações anatômicas de um organismo vivo, além de atuarem como enzimas, que catalisam as mais diversas reações metabólicas indispensáveis à vida.

Uma proteína pode estar no estado nativo $(\mathrm{N})$, em que apresenta a função para a qual foi produzida, ou no estado desnaturado (D), em que não apresenta uma função específica, embora ainda seja uma fonte de aminoácidos, que podem ser usados no catabolismo energético e em vários processos de biossíntese.

Uma proteína pode apresentar inúmeras conformações. Cada uma delas caracteriza um micro-estado. O conjunto ("ensemble") desses micro-estados compõe o macro-estado da proteína. O macroestado $\mathrm{N}$ é composto por uma quantidade pequena de micro-estados, uma vez que a estrutura da proteína não deve variar muito, para não comprometer sua função. Mas o macro-estado D pode apresentar um número muito elevado de micro-estados ${ }^{1,2}$.

Os estados $\mathrm{N}$ e D de uma proteína estão em equilíbrio

$\mathrm{N} \leftrightarrows \mathrm{D}$

onde predomina o estado que apresenta menor conteúdo de energia livre e, portanto, maior estabilidade ${ }^{1-4}$. Em soluções essencialmente aquosas, o estado $\mathrm{N}$ tem maior estabilidade, o que é fundamental para preservar a função da proteína. Vários fatores, como temperatura, $\mathrm{pH}$ e concentração de solutos, podem afetar o equilíbrio $\mathrm{N}-\mathrm{D}$, promovendo estabilização (do estado nativo) ou desnaturação. A estabilização e a desnaturação de proteínas são temas de grande interesse fisiológico ${ }^{5}$, terapêutico ${ }^{6,7}$ e biotecnológico ${ }^{8,9}$, onde o controle da estabilidade de uma proteína representa uma importante estratégia para manutenção de sua atividade biológica. Além disso, atualmente a análise da estabilidade se tornou um instrumento poderoso para caracterização de proteínas ${ }^{10-12}$, cada vez mais utilizado na literatura com este propósito ${ }^{13-16}$. A estabilização e

*e-mail: nspenha@ufu.br desnaturação de proteínas têm sido revistas em trabalhos clássi$\cos$, que mostram a natureza complexa desses processos ${ }^{17-22}$. O presente trabalho procura se inserir neste contexto, fazendo uma revisão analítica sobre a natureza termodinâmica do efeito da água pura, de caotrópicos e osmólitos sobre a estabilidade de proteínas em soluções aquosas.

\section{EQUILÍBRIO DE ESTABILIZAÇÃo DE PROTEÍNAS}

A estabilidade do estado nativo em relação ao estado desnaturado está intrinsecamente associada à constante de equilíbrio $\left(\mathrm{K}_{\mathrm{ND}}\right)$ entre aqueles estados ${ }^{17}$, a qual é definida pela igualdade

$\mathrm{K}_{\mathrm{ND}}=\frac{[\mathrm{D}]}{[\mathrm{N}]}$

A variação da energia livre de desnaturação $\left(\Delta \mathrm{G}_{\mathrm{ND}}\right)$ está relacionada com a variação de energia livre padrão de desnaturação $\left(\Delta \mathrm{G}_{\mathrm{ND}}^{\circ}\right)$ e a constante de equilíbrio $\left(\mathrm{K}_{\mathrm{ND}}\right)$, de acordo com a Equação:

$\Delta \mathrm{G}_{\mathrm{ND}}=\Delta \mathrm{G}_{\mathrm{ND}}^{\circ}+\mathrm{RT} \ln \mathrm{K}_{\mathrm{ND}}$

onde $\mathrm{R}\left(8,314 \mathrm{~J} \mathrm{~K}^{-1} \mathrm{~mol}^{-1}\right.$ ou $\left.1,987 \mathrm{cal} \mathrm{K}^{-1} \mathrm{~mol}^{-1}\right)$ é a constante universal dos gases e $\mathrm{T}$, a temperatura absoluta, em Kelvin.

Como no equilíbrio $\Delta \mathrm{G}_{\mathrm{ND}}$ é zero, a Equação 1 é reduzida à seguinte forma:

$\Delta \mathrm{G}_{\mathrm{ND}}^{\circ}=-\mathrm{RT} \ln \mathrm{K}_{\mathrm{ND}}$

$\mathrm{O}$ equilíbrio entre $\mathrm{N}$ e $\mathrm{D}$ pode ser caracterizado por três diferentes situações: 1) $[\mathrm{N}]>[\mathrm{D}]$, 2) $[\mathrm{N}]=[\mathrm{D}]$, e 3) $[\mathrm{N}]<[\mathrm{D}]$.

Quando a concentração de $\mathrm{N}$ é maior que a concentração de $\mathrm{D}$ no equilíbrio (situação 1), a constante $\mathrm{K}_{\mathrm{ND}}$ assume um valor menor que 1, conforme a Equação 2, o que significa que $\ln \mathrm{K}_{\mathrm{ND}}$ é um número negativo e, portanto, o valor de $\Delta \mathrm{G}^{\circ}{ }_{\mathrm{ND}}$ é positivo, em decorrência do sinal negativo presente no segundo membro da Equação 4. Nessa situação, a transição $\mathrm{N} \rightarrow \mathrm{D}$ não é espontânea e somente ocorre com fornecimento de energia a partir de condições 
padrões, que compreendem concentrações iguais a $1 \mathrm{~mol} \mathrm{~L}^{-1}$ para os estados $\mathrm{N}$ e D da proteína.

Quando a concentração de $\mathrm{N}$ é igual à concentração de $\mathrm{D}$ no equilíbrio (situação 2), a constante $\mathrm{K}_{\mathrm{ND}}$ assume valor 1 , conforme a Equação 2, o que significa que ln $\mathrm{K}_{\mathrm{ND}}$ é zero e, portanto, o valor de $\Delta \mathrm{G}^{\circ}{ }_{\mathrm{ND}}$ também é zero. Nessa situação não há transição espontânea entre os estados $\mathrm{N}$ e D sob condições padrões.

Quando a concentração de $\mathrm{N}$ é menor que a concentração de $\mathrm{D}$ ( situação 3), a constante $\mathrm{K}_{\mathrm{ND}}$ assume um valor maior que 1 , conforme a Equação 2, o que significa que $\ln \mathrm{K}_{\mathrm{ND}}$ será positivo e, portanto, o valor de $\Delta \mathrm{G}^{\circ}{ }_{\mathrm{ND}}$ será negativo, de acordo com a expressão 4. Isto significa que a transição $\mathrm{N} \rightarrow \mathrm{D}$ será espontânea sob condições padrões.

$\mathrm{O}$ equilíbrio N-D pode ser caracterizado por qualquer uma das três situações anteriores, dependendo de vários fatores, inclusive da composição do solvente.

A Figura 1 mostra definições utilizadas para valores de $\Delta \mathrm{G}^{\circ}{ }_{\mathrm{ND}}$ em solventes com diferentes composições.

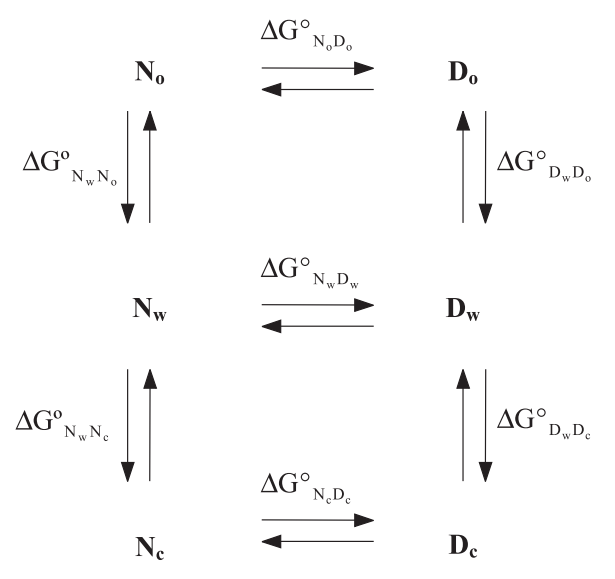

Figura 1. Definições das variações de energia livre padrão de desnaturação de uma proteína em água (w) e em soluções aquosas de osmólitos $(o)$ e de caotrópicos (c), juntamente com as variações de energia livre padrão de transferência dos estados nativo $(N)$ e desnaturado $(D)$ de uma proteína da água para soluções aquosas de osmólitos ou de caotrópicos

Como o equilíbrio N-U está normalmente ocorrendo em soluções aquosas, a interpretação do significado físico de $\Delta \mathrm{G}^{\circ}{ }_{\mathrm{ND}}$ deve considerar o equilíbrio de formação e quebra de ligações de hidrogênio, hidrofóbicas e iônicas no interior da proteína; o equilíbrio de interação de grupos da proteína com o solvente e, o equilíbrio de organização estrutural do solvente.

Esses processos de equilíbrio são afetados pela composição do solvente, mas também pela temperatura e pelo $\mathrm{pH}$.

\section{EQUILÍBRIO DE ESTABILIZAÇÃO DE PROTEÍNAS COMO UMA FUNÇÃO DA TEMPERATURA}

Embora o equilíbrio de estabilização de uma proteína seja muito bem definido pela variação de energia livre, que pode ser convenientemente limitada à temperatura padrão de $298,15 \mathrm{~K}$, muitas vezes seu estudo também é desenvolvido em função da temperatura, permitindo a avaliação das funções termodinâmicas de entalpia e entropia.

A variação de energia livre padrão de desnaturação pode ser relacionada com as variações de entalpia e de entropia pela Equação

$\Delta \mathrm{G}_{\mathrm{ND}}^{\circ}=\Delta \mathrm{H}_{\mathrm{ND}}^{\circ}-\mathrm{T} \Delta \mathrm{S}_{\mathrm{ND}}^{\circ}$
A equivalência entre as Equações 4 e 5 leva à chamada Equação de van’t Hoff

$\ln \mathrm{K}_{\mathrm{ND}}=-\frac{\Delta \mathrm{H}^{\circ}{ }_{\mathrm{ND}}}{\mathrm{R}} \cdot \frac{1}{\mathrm{~T}}+\frac{\Delta \mathrm{S}_{\mathrm{ND}}^{\circ}}{\mathrm{R}}$

que pode ser usada para determinação das variações de entalpia e de entropia a partir das constantes de equilíbrio de desnaturação da proteína, desde que haja uma relação linear entre $\ln \mathrm{K}_{\mathrm{ND}}$ e o inverso da temperatura absoluta, o que presume que $\Delta{\mathrm{H}^{\circ}}_{\mathrm{ND}}$ não seja uma função da temperatura no intervalo de temperatura utilizado. Muitas vezes esta condição não é válida em um intervalo mais amplo de temperatura, mas é válida em intervalos específicos de temperatura.

$\ln \mathrm{K}_{\mathrm{ND}}$ não apresenta uma relação linear com o inverso da temperatura absoluta quando o processo envolve uma alteração na capacidade calorífica $\left(\Delta \mathrm{C}_{\mathrm{p}}{ }^{\circ}\right)$. Nesse caso, $\Delta \mathrm{H}^{\circ}{ }_{\mathrm{ND}}$, que varia com a temperatura, pode ser determinada, por calorimetria, em uma dada temperatura T, pela Equação

$\Delta \mathrm{H}^{\circ}{ }_{\mathrm{ND}_{\mathrm{T}}}=\Delta \mathrm{H}_{\mathrm{ND}_{0}}+\int_{0}^{\mathrm{T}} \Delta \mathrm{C}_{\mathrm{p}_{\mathrm{ND}}} \mathrm{dT}$

onde $\Delta \mathrm{H}^{\circ}{ }_{\mathrm{ND}_{0}}$ é a variação de entalpia a $0 \mathrm{~K}$; enquanto $\Delta \mathrm{S}^{\circ}{ }_{\mathrm{ND}}$ pode ser determinada por

$\Delta \mathrm{S}_{\mathrm{ND}}^{\circ}=\int_{0}^{\mathrm{T}} \frac{\Delta \mathrm{C}_{\mathrm{p}}}{\mathrm{T}} \mathrm{dT}$

desde que $\Delta \mathrm{C}_{\mathrm{p}}{ }^{\circ}$ não seja também ela própria uma função da temperatura. A partir das variações de entalpia e de entropia, é também possível determinar a variação de energia livre a uma dada temperatura $\left(\Delta \mathrm{G}^{\circ}{ }_{\mathrm{ND}_{\mathrm{T}}}\right)$

$\Delta \mathrm{G}_{\mathrm{ND}_{\mathrm{T}}}^{\circ}=\Delta \mathrm{H}_{\mathrm{ND}_{0}}+\int_{0}^{\mathrm{T}} \Delta \mathrm{C}_{\mathrm{p}_{\mathrm{ND}}} \mathrm{dT}-\mathrm{T} \int_{0}^{\mathrm{T}} \frac{\Delta \mathrm{C}_{\mathrm{p}}}{\mathrm{T}} \mathrm{dT}$

obtida pela substituição das Equações 7 e 8 na Equação 5.

A variação de energia livre depende da temperatura segundo uma curva de formato gaussiano, cujo ponto máximo caracteriza a temperatura de maior estabilidade da proteína ${ }^{9}$. Essa temperatura deve ser tanto maior quanto mais intensas são as forças que mantêm a proteína no estado $\mathrm{N}$.

O calor, por si só, é um agente caotrópico, pois aumenta a entropia vibracional dos grupamentos da proteína, o que favorece a ruptura das ligações não covalentes que estabilizam o estado $\mathrm{N}$, promovendo sua desnaturação. A quebra de ligações decorrente do aumento da vibração de grupos deve constituir um processo endotérmico $\left(\Delta \mathrm{H}^{\circ}{ }_{\mathrm{ND}}>0\right)$. Como esse aumento na entropia vibracional $\left(\Delta \mathrm{S}_{\mathrm{ND}}^{\circ}>0\right)$ está associado ao gasto de calor envolvido na quebra das ligações do estado nativo, pode-se dizer que o aumento na entalpia é compensado por um aumento de entropia, o que poderia ser a base da compensação entalpia-entropia verificada para os processos de desnaturação térmica de proteínas ${ }^{23}$.

\section{EQUILÍBRIO DE ESTABILIZAÇÃO DE PROTEÍNAS COMO UMA FUNÇÃO DO pH}

$\mathrm{O} \mathrm{pH}$ caracteriza o equilíbrio entre íons $\mathrm{H}^{+}$e $\mathrm{OH}^{-}$de uma solução e sua mudança afeta o equilíbrio de ionização de grupos ácidos e básicos de uma proteína. Assim, mudanças no pH vão afetar a distribuição de cargas de uma proteína e, conseqüentemente, as interações eletrostáticas entre grupos da proteína, entre a proteína e o solvente e entre as próprias moléculas do solvente ${ }^{20,24-26}$.

A mudança do $\mathrm{pH}$ do meio de um valor i para um valor $\mathrm{j}$ vai promover alterações na energia livre tanto do estado $\mathrm{N}$ quanto do 
estado D, as quais podem ser determinadas pelas Equações ${ }^{25,27-31}$

$\Delta G^{\circ}{ }_{{ }_{p H i j}}=2,303 R T \int_{p H_{i}}^{p H_{j}} v_{N} d p H(\mathrm{v})$

$\mathrm{e}$

$\Delta G_{U_{p H_{i j}}}^{\circ}=2,303 R T \int_{p H_{i}}^{p H_{j}} v_{U} d p H(\mathrm{v})$

onde $v$ é o estado de protonação relativo da proteína e $\mathrm{dpH}(\mathrm{v})$, é a derivada de $\mathrm{pH}$ em função de $\mathrm{v}$.

A partir das Equações 10 e 11, é possível derivar uma equação para determinar o valor de $\Delta \mathrm{G}^{\circ}{ }_{\mathrm{ND}}$ entre os valores de $\mathrm{pH}$ i e j j7-29

$\Delta G^{\circ}{ }_{N D_{p H_{i j}}}=2,303 R T \int_{p H_{i}}^{p H_{j}}\left(\mathrm{v}_{U}-\mathrm{v}_{N}\right) d p H$

\section{EQUILÍBRIO DE ESTABILIZAÇÃO DE PROTEÍNAS EM SOLUÇÕES ESSENCIALMENTE AQUOSAS}

Sob um ponto de vista estatístico, o "ensemble" desnaturado deveria predominar sobre o ensemble nativo, devido ao seu número de micro-estados mais elevado, pois isso lhe garantiria uma entropia conformacional mais elevada ${ }^{1,2,4,32}$.

Entretanto, sob certas condições, o estado nativo prevalece sobre o estado desnaturado. Isso acontece principalmente em meio aquoso, como no interior ou exterior de uma célula. A explicação para este aparente paradoxo decorre da interação da proteína com as moléculas de água ${ }^{32}$.

Em meio aquoso, as formas nativa e desnaturada estão rodeadas por moléculas de água, organizadas em camadas de hidratação ao redor da proteína. A quantidade de energia livre envolvida na hidratação é proporcional ao tamanho da camada de hidratação formada. Como a forma desnaturada apresenta maior superfície de exposição ao solvente, sua camada de hidratação é mais extensa (Figura 2) e, conseqüentemente, maior é a energia livre necessária para sua hidratação. Por outro lado, como a forma nativa apresenta menor superfície de exposição ao solvente, tem uma camada de hidratação menos extensa e, conseqüentemente, requer menos energia livre para sua hidratação.

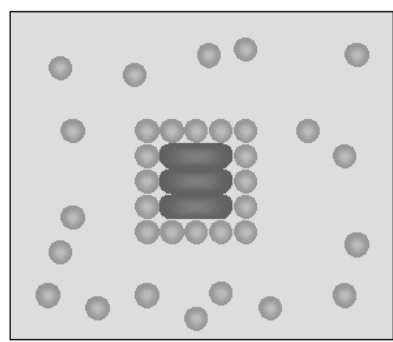

a

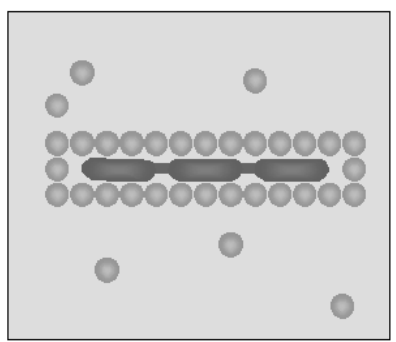

b
Figura 2. Ilustração de moléculas de água (esferas em cinza) formando uma camada de hidratação ao redor de uma proteína (estruturas retangulares escuras) tanto no estado nativo (a) como no estado desenovelado (b). Podese perceber que, no estado nativo, por estar mais compactada, a superfície da proteína em contato com o solvente é menos extensa e, conseqüentemente, a camada de hidratação que se forma ao redor desse estado é menor que a formada ao redor do estado desenovelado

Embora o estado D apresente uma entropia conformacional mais elevada que o estado $\mathrm{N}$, o estado $\mathrm{D}$ requer uma quantidade de energia livre de hidratação muito mais elevada que o estado N. Em água pura, a elevada energia livre necessária para hidratação do estado D não é compensada pela sua entropia conformacional. A energia livre requerida para formação da camada de hidratação vem das interações hidrofóbicas entre grupamentos apolares de aminoácidos; como no estado desenovelado estes grupamentos estão expostos ao solvente, a interação da proteína com a água não fornece a energia necessária para formação da camada de hidratação.

Embora o estado $\mathrm{N}$ apresente uma entropia conformacional mais baixa que o estado $\mathrm{D}$, a energia livre de hidratação também é mais baixa e facilmente obtida pela força hidrofóbica que compele os grupos apolares da proteína a ficarem juntos, com baixa entropia conformacional, no interior anidro da macromolécula. Assim, no estado N, a baixa entropia conformacional é compensada pela energia livre de enovelamento da proteína, que também atende à demanda energética envolvida na formação de sua camada de hidratação.

Isso significa que o equilíbrio entre estados $\mathrm{N}$ e $\mathrm{D}$ da proteína vai estar deslocado no sentido do estado nativo (Figura 3a), que é mais estável quando o ambiente é essencialmente aquoso ${ }^{32}$.

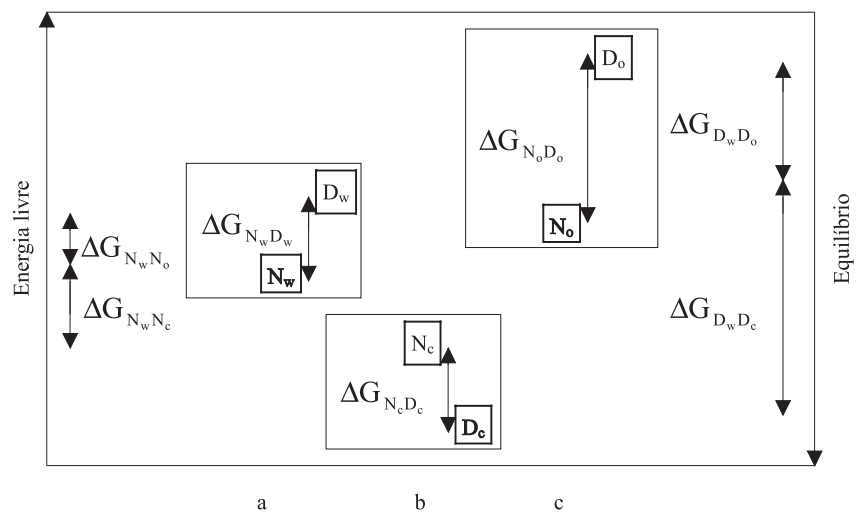

Figura 3. Equilíbrio N-U na presença de água pura (a) e de soluções aquosas de um caotrópico (b) e de um osmólito (c)

\section{EQUILÍBRIO DE ESTABILIZAÇÃO DE PROTEÍNAS EM SOLUÇÕES AQUOSAS DE CAOTRÓPICOS}

Embora a água pura favoreça o estado $\mathrm{N}$ de uma proteína, existem várias condições que podem afetar o equilíbrio entre os estados $\mathrm{N}$ e D.

Algumas células ou líquidos corporais possuem solutos que podem comprometer a atividade biológica de uma proteína, como a uréia ${ }^{2,22,33-39}$, cuja afinidade pelo estado D inspirou o termo caotrópico para designação deste tipo de desnaturante, uma vez que o estado desenovelado de uma proteína deve ter uma estrutura de espiral randômica ${ }^{4,17,18,30,40}$. A uréia é produzida em nosso organismo, como produto de degradação e excreção do grupo amino de aminoácidos, e está presente no fígado, onde é produzida; no sangue, por onde é transportada; e nos rins, por onde é excretada na urina.

Outro desnaturante com ação semelhante à da uréia é o hidrocloreto de guanidina ${ }^{2,22,33,39}$.

O mecanismo de ação desses caotrópicos ainda é motivo de controvérsia ${ }^{4,21,39,41-44}$.

A ação desnaturante da uréia e do hidrocloreto de guanidina poderia ser decorrente de elevações na solubilidade de grupos da proteína na solução aquosa do desnaturante, o que está expresso na Equação

$\Delta \mathrm{G}_{\mathrm{ND}[\mathrm{D}]}^{\circ}=\Delta \mathrm{G}_{\mathrm{ND}\left[\mathrm{H}_{2} \mathrm{O}\right]}^{\circ}+\sum_{\mathrm{i}} \alpha_{\mathrm{i}} \mathrm{n}_{\mathrm{i}} \delta \mathrm{g}_{\mathrm{tr}_{\mathrm{i}}}$ 
onde $\Delta \mathrm{G}^{\circ}{ }_{\mathrm{ND}[\mathrm{D}]}$ e $\Delta \mathrm{G}^{\circ}{ }_{\mathrm{ND}\left[\mathrm{H}_{2} \mathrm{O}\right]}$ são, respectivamente, as variações de energia livre de desnaturação na presença de uma dada concentração do desnaturante [D] e em água pura $\left[\mathrm{H}_{2} \mathrm{O}\right]$, n é o número de resíduos de um dado grupo i presente na proteína, $\alpha_{i}$ é a mudança fracional média do grau de exposição de cada grupo e $\delta g_{t_{i}}$ é a variação de energia livre de transferência deste grupo da água pura para a concentração considerada do desnaturante ${ }^{30}$. A natureza favorável da transferência das cadeias laterais de quase todos os aminoácidos, inclusive daquelas apolares, e das ligações peptídicas $\left(\delta g_{\text {tr }}<0\right)$ da água para soluções aquosas de uréia e de hidrocloreto de guanidina ${ }^{4,45}$ é consistente com essa idéia. De fato, a solubilidade do próprio benzeno aumenta significantemente com o aumento da concentração de hidrocloreto de guanidina ${ }^{35}$, de tal forma que o caotrópico estará não somente acomodando os grupos apolares no solvente como também diminuindo a força hidrofóbica, que é um fator essencial na formação e estabilização do estado nativo de uma proteína ${ }^{4,45}$.

Entretanto, a variação favorável de energia livre de transferência de grupos da proteína para o desnaturante poderia ser decorrente da ligação das moléculas do desnaturante à ligação peptídica e/ou às cadeias laterais dos aminoácidos, de tal modo que

$\delta g_{\text {tr }}=\mathrm{RT} \ln (1+\mathrm{ka})$

$\Delta \mathrm{G}_{\mathrm{ND}_{[\mathrm{D}]}}^{\circ}=\Delta \mathrm{G}_{\mathrm{ND}\left[\mathrm{H}_{2} \mathrm{O}\right]}^{\circ}-\Delta \mathrm{nRT} \ln (1+\mathrm{ka})$

onde k é a constante de ligação e a é a atividade do desnaturante ${ }^{30,46}$. Como o estado D tem maior exposição de sítios para ligação de uréia que o estado $\mathrm{N}^{47}$, a hidratação da proteína mediada pela uréia deve ser maior no estado $\mathrm{D}$ que no estado $\mathrm{N}$, de tal forma que o estado D deve ser favorecido pela uréia. O hidrocloreto de guanidina também forma ligações de hidrogênio com grupos das cadeias laterais dos aminoácidos e das ligações peptídicas ${ }^{48,49}$, que também estão mais acessíveis ao caotrópico no estado desnaturado.

$\mathrm{O}$ etanol é um caotrópico anfifílico, com um segmento hidrocarbonado hidrofóbico $\left(-\mathrm{CH}_{2}-\mathrm{CH}_{2}-\right)$ junto com um grupo hidrofílico $(-\mathrm{OH})$. Ele pode se misturar com a água e acomodar melhor no solvente os grupos apolares da proteína, atenuando a força hidrofóbica, de tal forma a desfavorecer o estado nativo em detrimento do estado desnaturado ${ }^{50}$. De fato, a transferência das cadeias laterais apolares da água para o etanol apresenta valores de $\delta g_{\text {tr }}$ negativos, $o$ que evidencia a natureza favorável do processo ${ }^{45}$. Como o valor de $\delta g_{\text {tr }}$ para transferência do esqueleto peptídico da água para o etanol é positivo, isto significa que é a maior afinidade das cadeias laterais da proteína pelo etanol que determina a desnaturação $0^{45}$.

De maneira geral, o caotrópico diminui a energia livre do estado $\mathrm{D}$ em relação ao estado $\mathrm{N}$ de uma proteína (Figura 3b), deslocando o equilíbrio N-D no sentido do estado desnaturado.

\section{EQUILÍBRIO DE ESTABILIZAÇÃO DE PROTEÍNAS EM SOLUÇÕES AQUOSAS DE OSMÓLITOS}

Para proteger suas proteínas contra situações naturais de estresse, como o aumento excessivo da concentração de uréia, da acidez e da temperatura, os organismos vivos tiveram que se adaptar evolutivamente a altas concentrações de certos solutos orgânicos, como açúcares, álcoois e alguns aminoácidos, coletivamente designados como osmólitos ${ }^{50-54}$ ou cosmotrópicos ${ }^{5-57}$.

De fato, vários trabalhos têm mostrado que os osmólitos estabilizam proteínas contra caotrópicos ${ }^{36,37,58,59}$, acidez ${ }^{54,58,60,61}$, diminuições ${ }^{5,58}$ ou elevações na temperatura ${ }^{58,60,62,63}$, altas pressões $^{58} \mathrm{e}$ baixa atividade de água ${ }^{52,58}$.

Os osmólitos elevam a energia livre de desnaturação das prote- ínas, de tal forma que $\Delta \mathrm{G}^{\circ}{ }_{\mathrm{NoDo}}>\Delta \mathrm{G}^{\circ}{ }_{\mathrm{NwDw}}^{32,64-68}$.

A explicação mais ampla e aceita para esse efeito foi fundamentada na interação preferencial da água com a proteína ${ }^{21}$, com base na teoria das funções de Wyman ${ }^{69,70}$, que permitiu construir a relação

$\left(\frac{\partial \ln K}{\partial \ln a_{x}}\right)_{T, P, a_{j \neq x}}=\overline{\mathbf{V}}_{x}^{\text {produto }}-\overline{\mathbf{V}}_{x}^{\text {reagente }}=\Delta \overline{\mathbf{V}}_{x}$

onde $\mathrm{K}$ é a constante de equilíbrio de uma reação reagente $\leftrightarrows$ produto, que é modulada por um ligante $\mathrm{x} ; \overline{\mathrm{v}}_{\mathrm{x}}$ representa a associação de um ligante ao reagente e ao produto; e T, P e $a_{\mathrm{j}}$ são, respectivamente, temperatura, pressão e atividade do componente j. A racionalidade desta relação fundamenta-se no fato de que se um processo químico é controlado por um fator $\mathrm{x}$, que nesse caso é o osmólito, então a extensão de ligação de x irá mudar durante o curso da reação.

A incorporação de um osmólito (x) em uma solução aquosa de proteína $(\mathrm{P})$ vai conduzir ao equilíbrio

$\mathrm{P} \cdot\left(\mathrm{H}_{2} \mathrm{O}\right) \mathrm{n}+\mathrm{x}=\mathrm{P} \cdot \mathrm{x}+\mathrm{n} \mathrm{H}_{2} \mathrm{O}$

onde há competição entre a água e o osmólito pela proteína.

Esta competição é vencida pela água, ou seja, a proteína prefere ligar-se às moléculas de água que ao osmólito, que é então preferencialmente excluído da superfície da proteína, segundo um efeito que foi denominado de efeito solvofóbico ${ }^{32,64,65}$ ou osmofóbico ${ }^{71}$. Este efeito pode ser explicado pela maior afinidade pela água que pela mistura osmólito-água dos grupos apolares ${ }^{64,65}$ e do esqueleto peptídico $^{68}$ da proteína. De qualquer forma, a competição gerada entre o osmólito e a água pela proteína eleva a energia livre de hidratação tanto do estado $\mathrm{N}\left(\Delta \mathrm{G}^{\circ}{ }_{\mathrm{NwNo}}\right)$ quanto do estado $\mathrm{D}$ $\left(\Delta \mathrm{G}_{\text {DwDo }}^{\circ}\right)$ da proteína. Como os grupos apolares e o esqueleto peptídico estão mais expostos ao solvente no estado desnaturado que no estado nativo, o estado desnaturado é mais desestabilizado que o estado nativo da proteína, ou seja $\Delta \mathrm{G}^{\circ}{ }_{\text {NoDo }}>\Delta \mathrm{G}^{\circ}{ }_{\mathrm{NwDw}}$ (Figura $3 \mathrm{c})$. Isso significa que o osmólito estabiliza o estado nativo de uma proteína em relação ao estado desnaturado ${ }^{32,64-68}$.

É possível que a estabilização osmofóbica de uma proteína esteja associada ou compreenda a ação conjunta de outros fatores, como a exclusão espacial do osmólito e alterações na constante dielétrica e na viscosidade da solução ${ }^{36,37,50,72-75}$.

$\mathrm{O}$ tratamento dado pela aplicação das funções de Wyman à interação de proteínas com osmólitos apresenta uma validade muito mais ampla e pode justificar uma gama muito variada de fenômenos aparentemente dissociados, como o equilíbrio N-D e o equilíbrio R-T ${ }^{21}$.

O equilíbrio entre os estados $\mathrm{T}$ (apertado) e $\mathrm{R}$ (relaxado) da hemoglobina e, conseqüentemente, a capacidade de ligação e regulação da ligação de oxigênio podem ser afetados pelo estresse osmótico. Como a conversão T-R envolve a ligação de mais cerca de 60 moléculas de água à hemoglobina, a hidratação da hemoglobina deve afetar seu equilíbrio de oxigenação. A análise dos efeitos do estresse osmótico sobre a oxigenação da hemoglobina, com base nas funções de Wyman, mostrou que as alterações na atividade da água, produzidas pelo estresse osmótico, podem afetar o equilíbrio T-R, sugerindo que a água seja um efetor alostérico daquela proteína ${ }^{76-78}$.

\section{CONSIDERAÇÕES FINAIS}

A influência de solutos sobre o equilíbrio de estabilização de proteínas é um processo corrente nos organismos vivos. A comple- 
xidade do ambiente in vivo das proteínas exige uma análise detalhada in vitro de cada uma das diferentes condições ambientais naturais, para possibilitar maior compreensão dos mecanismos de ação dos diferentes agentes naturais capazes de perturbar o equilíbrio entre os estados $\mathrm{N}$ e D da proteína. Os estudos in vitro também podem permitir a simulação de uma variedade de situações capazes de alterar o equilíbrio de estabilização de uma proteína, dando suporte crescente para sua utilização biotecnológica.

Uma aplicação biotecnológica importante é a promoção do enovelamento de proteínas ${ }^{6,79}$. Esta questão é muito importante, pois o enovelamento defeituoso de proteínas é a causa de um grande número de doenças ${ }^{80}$. Se a incorporação do osmólito à solução aquosa da proteína aumenta a tensão interfacial entre grupos apolares e esqueleto peptídico com o solvente, forçando a proteína a esconder seus grupos osmofóbicos no estado nativo da proteína, seria de se esperar que os osmólitos tivessem a propriedade de estimular o enovelamento protéico. De fato, vários osmólitos foram capazes de diminuir a entropia conformacional e aumentar a densidade de grupos hidrofóbicos de RNAse A reduzida e carboxiamidometilada (RCAM-Rnase A), o que significa que eles estariam forçando a proteína a se enovelar ${ }^{75,81}$. Alguns osmólitos naturais se mostraram capazes de induzir a polimerização de microtúbulos induzida pela proteína tau ${ }^{82}$. Algumas proteínas com defeitos de enovelamento sensíveis à temperatura, como a proteína reguladora do transporte de íons cloreto ( $\triangle \mathrm{F} 508-\mathrm{CFTR})$, cujo defeito promove a fibrose cística, e a proteína supressora de tumores p53, cujo defeito propicia o desenvolvimento de câncer, sofreram enovelamentos corretos a $39,5^{\circ} \mathrm{C}$ na presença de vários osmólitos, o que somente ocorreria se as proteínas fossem incubadas à temperatura de $32,5^{\circ} \mathrm{C}^{7,83}$. Até a formação defeituosa do príon scrapie (PrPSc), causador de diversas doenças caracterizadas por encefalopatia espongiforme, seria impedida na presença de osmólitos, com o enovelamento correto da proteína para a forma fisiológica, conhecida como príon celular (PrPC ${ }^{84}$. É possível que o uso de osmólitos possa ter eficácia para prevenir o enovelamento patológico da proteína amilóide, com formação da proteína $\beta$-amilóide, presente nas placas amilóides de portadores da doença de Alzheimer. Há uma expectativa de que o uso de osmólitos possa vir a constituir uma alternativa segura e eficaz à terapia gênica ${ }^{7}$.

No que se refere às aplicações biotecnológicas, é importante destacar que o uso de osmólitos e caotrópicos pode ser uma alternativa importante para o melhoramento celular de microrganismos utilizados na produção industrial de derivados fermentados, para conservação de vacinas ${ }^{85}$ e criopreservação de tecidos, embriões e células $^{5}$, dentre outras aplicações.

\section{REFERÊNCIAS}

1. Tanford, C.; J. Am. Chem. Soc. 1962, 84, 4240

2. Tanford, C.; J. Am. Chem. Soc. 1963, 86, 2050.

3. Anfinsen, C. B.; J. Polym. Sci. 1961, 49, 31.

4. Nozaki, Y.; Tanford, C.; J. Biol. Chem. 1963, 238, 4074

5. Storey, K. B.; Mosser, D. D.; Douglas, D. N.; Grundy, J. E.; Storey, J. N.; Braz. J. Med. Bio. Res. 1996, 29, 283.

6. Welch, W. J.; Brown, C. R.; Cell Stress Chaperones 1996, 1, 109.

7. Brown, C. R.; Hong-Brown, L. Q.; Welch, W. J.; J. Clin. Invest. 1997, 99, 1432.

8. Panek, A. D.; Braz. J. Med. Bio. Res. 1995, 28, 169

9. Lee, J. C.; Curr. Opin. Biotechnol. 2000, 11, 81

10. Pace, C. N. Em Methods in Enzymology; Hirs, C. H. W.; Timasheff, S. N., eds.; Academic: New York, 1986, cap. 14

11. Santoro, M. M.; Bolen, D. W.; Biochemistry 1992, 31, 4901.

12. Pace, C. N.; Shirley, B. A.; Thompson, J. A. Em Protein structure: a practical approach; Creighton, T. E., ed.; IRL: Oxford, 1989, cap. 13.

13. Brumano, M. H. N.; Rogana, E.; Swaisgood, H. E.; Arch. Biochem. Biophys. 2000, 382, 57.
14. Brito, A. G.; Soares, A.; Homsi-Brandeburgo, M. I.; Borges, M. H.; Giglio, J. R.; Penha-Silva, N.; Protein Pept. Lett. 2003, 10, 85.

15. Bittar, E. R.; Caldeira, F. R.; Santos, A. M. C.; Günther, A. R.; Rogana, E.; Santoro, M. M.; Braz. J. Med. Bio. Res. 2003, 36, 1621.

16. Brumano, M. H. N.; Oliveira, M. G. A.; Protein Pept. Lett. 2004, 11, 133.

17. Kauzmann, W.; Adv. Prot. Chem. 1959, 14, 1.

18. Tanford, C.; Adv. Prot. Chem. 1968, 23, 121.

19. Privalov, P. L.; Gill, S. J.; Adv. Prot. Chem. 1988, 39, 191

20. Dill, K. A.; Shortle, D.; Annu. Rev. Biochem. 1991, 60, 795.

21. Timasheff, S. N.; Adv. Prot. Chem. 1998, 51, 355.

22. Schellman, J. A.; Biophys. Chem. 2002, 96, 91.

23. Cooper, A.; Curr. Opin. Chem. Biol. 1999, 3, 557.

24. Tanford, C.; Adv. Prot. Chem. 1962, 17, 69.

25. Yang, A. S.; Honig, B.; Curr. Opin. Struct. Biol. 1992, 2, 40.

26. Chi, E. Y.; Krishnan, S.; Randolph, T. W.; Carpenter, J. F.; Pharm. Res. 2003, 20, 1325.

27. Pfeil, W.; Privalov, P. L.; Biophys. Chem. 1976, 4, 23.

28. Schellman, J.; Halkes, R. Em Protein Folding; Jaenicke, R., ed.; Elsevier: New York, 1980, pp. 331-343.

29. Hermans, J., Jr.; Acampora, G.; J. Am. Chem. Soc. 1967, 89, 1547.

30. Tanford, C.; Adv. Prot. Chem. 1970, 24, 1.

31. Chu, A.; Turner, B. W.;Ackers, G. K.; Biochemistry 1984, 23, 604.

32. Timasheff, S. N.; Arakawa, T. Em ref. 12, cap. 14.

33. Hopkins, F. G.; Nature 1930, 126, 328.

34. Neurath, H.; Greenstein, J. P.; Putnam, F. W.; Erickson, J. O.; Chem. Rev. 1944, 34, 157.

35. Breslow, R.; Guo, T.; Proc. Natl. Acad. Sci. U. S. A. 1990, 87, 167.

36. Taylor, L. S.; York, P.; Williams, A. C.; Edwards, H. G. M.; Mehta, C.; Jackson, G. S.; Badcoe, I. G.; Clarke, A. R.; Biochim. Biophys. Acta 1995, 1253, 39.

37. Wang, A.; Bolen, D. W.; Biochemistry 1997, 36, 9101.

38. Pace, C.; Shaw, K. L.; Proteins: Struct., Funct. Genet. 2000, 41, 1.

39. Bennion, B. J.; Daggett, V.; Proc. Natl. Acad. Sci. U. S. A. 2003, 100, 5142.

40. Pace, C. N.; Vanderburg, K. E.; Biochemistry 1979, 18, 288.

41. von Hippel, P. H.; Schleich, T.; Acc. Chem. Res. 1969, 2, 257.

42. Tsai, J.; Gerstein, M.; Levitt, M.; J. Chem. Phys. 1996, 104, 9417.

43. Schellman, J. A.; Biopolymers 1978, 14, 999.

44. Zou, Q.; Bennion, B. J.; Daggett, V.; Murphy, K.; J. Am. Chem. Soc. 2002, $124,1192$.

45. Nozaki, Y.; Tanford, C.; J. Biol. Chem. 1971, 246, 2211.

46. Pace, C. N.; Crit. Rev. Biochem. 1975, 3, 1.

47. Makhatadze, G. I.; Privalov, P. L.; J. Mol. Biol. 1992, 226, 491.

48. Gianni, S.; Brunori, M.; Travaglini-Allocatelli, C.; Protein Sci. 2001, 10, 1685.

49. Ho, J. G. S.; Middelberg, A. P. J.; Ramage, P.; Kocher, H. P.; Protein Sci. 2003, 12, 708 .

50. Wang, A.; Robertson, A. D.; Bolen, D. W.; Biochemistry 1995, 34, 15096.

51. Brown, A. D.; Simpson, J. R.; J. Gen. Microbiol. 1972, 72, 589.

52. Borowitzka, L. J.; Brown, A. D.; Arch. Microbiol. 1974, 96, 37.

53. Bowlus, R. D.; Somero, G. N.; J. Exp. Zool. 1979, $208,137$.

54. Somero, G.; Am. J. Physiol. 1986, 251, R-197.

55. Galinski, E. A.; Stein, M.; Amendt, B.; Kinder, M.; Comp. Biochem. Physiol., Part A: Mol. Integr. Physiol. 1997, 117, 357.

56. Moelbert, S.; Normand, B.; De Los Rios, P.; Biophys. Chem. 2004, 112, 45 .

57. Smith, P. E.; Biophys. Chem. 2005, 113, 299.

58. Jaenicke, R.; Závodsky, P.; FEBS Lett. 1990, $268,344$.

59. Lien, Y.-H. H.; Pacelli, M. M.; Braun, E. J.; Am. J. Physiol. 1993, 264, R1045.

60. Carpenter, J. F.; Crowe, J. H.; Cryobiology 1988, 25, 244.

61. Yancey, P. H.; Burg, M. B.; Am. J. Physiol. 1990, 258, R198.

62. Rishi, V.; Anjum, F.; Ahmad, F.; Pfeil, W.; Biochem. J. 1998, 329, 137.

63. Santoro, M. M.; Liu, Y.; Khan, S. M. A.; Hou, L.-X.; Bolen, D. W.; Biochemistry 1992, 31, 5278.

64. Gekko, K.; Timasheff, S. N.; Biochemistry 1981a, 20, 4667.

65. Gekko, K.; Timasheff, S. N.; Biochemistry 1981b, $20,4677$.

66. Lee, J. C.; Timasheff, S. N.; J. Biol. Chem. 1981, 256, 7193.

67. Timasheff, S. N.; Annu. Rev. Biophys. Biomol. Struct. 1993, 22, 67.

68. Liu, Y.; Bolen, D. W.; Biochemistry 1995, 34, 12884.

69. Wyman, J.; Adv. Protein Chem. 1964, 19, 223.

70. Wyman, J.; Gill, S. J.; Binding and Linkage. Functional Chemistry of Biological Macromolecules; University Science Books: Mill Valley, 1990.

71. Bolen, D. W.; Baskakov, I. V.; J. Mol. Biol. 2001, 310, 955.

72. Yancey, P. H.; Am. Zool. 2001, 41, 699.

73. Fields, P. A.; Comp. Biochem. Physiol., Part A: Mol. Integr. Physiol. 2001, $129,417$.

74. Saunders, A. J.; Davis-Searles, P. R.; Allen, D. L.; Pielak, G. J.; Erie, D. A.; Biopolymers 2000, 53, 293. 
75. Qu, Y.; Bolen, C. L.; Bolen, D. W.; Proc. Natl. Acad. Sci. U. S. A. 1998, 95, 9268.

76. Colombo, M. F.; Rau, D. C.; Parsegian, V. A.; Science 1992, 256, 655.

77. Colombo, M. F.; Rau, D. C.; Parsegian, V. A.; Proc. Natl. Acad. Sci. U. S. A. 1994, 91, 10517.

78. Colombo, M. F.; Bonilla-Rodriguez, G. O.; J. Biol. Chem. 1996, 271, 4895.

79. Sadana, A.; Vo-Dinh, T.; Biotechnol. Appl. Biochem. 2001, 33, 7.

80. Thomas, P. J.; Qu, B. H.; Pedersen, P. L.; TIBS 1995, 20, 456.
81. Baskakov, I.; Bolen, D. W.; J. Biol. Chem. 1998, 273, 4831.

82. Tseng, H.-C.; Graves, D. J.; Biochem. Biophys. Res. Commun. 1998, 250 , 726.

83. Brown, C. R.; Hong-Brown, L. Q.; Biwersi, J.; Verkman, A. S.; Welch, W. J.; Cell Stress Chaperones 1996, 1, 117.

84. Tatzelt, J.; Prusiner, S. B.; Welch, W. J.; EMBO J. 1996, 15, 6363.

85. Rodrigues-Silva, R.; Antunes, G. F. C.; Velarde, D. T.; Santoro, M. M.; Toxicon 1999, 37, 33. 